\title{
Immuno-PET imaging for non-invasive assessment of cetuximab accumulation in non-small cell lung cancer
}

\author{
Aiko Yamaguchi ${ }^{1,2+}$, Arifudin Achmad ${ }^{3,4,5+}$, Hirofumi Hanaoka ${ }^{1 *}$ (D, Yusri Dwi Heryanto ${ }^{3}$, Anu Bhattarai ${ }^{3}$, Ratianto ${ }^{3}$, \\ Erdene Khongorzul ${ }^{3}$, Rini Shintawati, ${ }^{3,4}$, A. Adhipatria P. Kartamihardja ${ }^{3,4}$, Ayaka Kanai $^{1}$, Yumi Sugo $^{6}$, \\ Noriko S. Ishioka ${ }^{6}$, Tetsuya Higuchi ${ }^{3}$ and Yoshito Tsushima ${ }^{3}$
}

\begin{abstract}
Backgrounds: Overexpression of epidermal growth factor receptor (EGFR) has been established as a valid therapeutic target of non-small cell lung cancer (NSCLC). However, the clinical benefit of cetuximab as an EGFRtargeting drug is still controversial, partially due to the lack of effective means to identify suitable patients. This study aimed to investigate the potential of radiolabeled cetuximab as a non-invasive tool to predict cetuximab accumulation in NSCLC tumor xenografts with varying EGFR expression levels.
\end{abstract}

Methods: The NSCLC tumors in model mice were subjected to in vivo biodistribution study and positron emission tomography (PET) imaging $48 \mathrm{~h}$ after injection of either ${ }^{111} \mathrm{In}$ - or ${ }^{64} \mathrm{Cu}$-labeled cetuximab. The EGFR expression levels of NSCLC tumors were determined by ex vivo immunoblotting.

Results: We found that tumors with high EGFR expression had significantly higher $\left[{ }^{111} \mathrm{In}\right] \mathrm{In}$-DOTA-cetuximab accumulation than tumors with moderate to low EGFR expression $(P<0.05)$. Strong correlations were found between $\left[{ }^{111} \mathrm{In}\right] \mathrm{In}$-DOTA-cetuximab tumor uptake and EGFR expression level $(r=0.893)$, and between $\left[{ }^{64} \mathrm{Cu}\right] \mathrm{Cu}$ DOTA-cetuximab tumor uptake with EGFR expression level $(r=0.915)$. PET imaging with $\left[{ }^{64} \mathrm{Cu}\right.$ Cu-DOTA-cetuximab allowed clear visualization of tumors.

Conclusion: Our findings suggest that this immuno-PET imaging can be clinically translated as a tool to predict cetuximab accumulation in NSCLC cancer patients prior to cetuximab therapy.

Keywords: Immuno-PET, Non-small cell lung cancer, Cetuximab, ${ }^{64} \mathrm{Cu}$, Personalized medicine, EGFR

\section{Background}

Non-small cell lung cancer (NSCLC) remains a deadly cancer worldwide, even with advances in treatment strategies such as molecular targeted therapy and immunotherapy [1]. Overexpression of epidermal growth factor receptor (EGFR) plays a role in NSCLC, making anti-EGFR drugs an attractive therapeutic option for this cancer. Tyrosine kinase inhibitors (TKIs) targeting EGFR are currently recommended as first-line therapy in patients with advanced NSCLC harboring an EGFR tyrosine-kinase domain

\footnotetext{
* Correspondence: hanaokah@gunma-u.ac.jp

${ }^{+}$Aiko Yamaguchi and Arifudin Achmad contributed equally to this work. ${ }^{1}$ Department of Bioimaging Information Analysis, Gunma University Graduate School of Medicine, 3-39-22 Showa-machi, Maebashi 371-8511, Japan Full list of author information is available at the end of the article
}

mutation. However, acquired resistance to TKIs is common and their modest effect in NSCLC patients without EGFR mutation necessitates alternative therapeutic approaches targeting EGFR [2].

Cetuximab, a recombinant, human/mouse chimeric monoclonal antibody that specifically targets the extracellular domain of EGFR, has demonstrated favorable efficacy in combination with platinum-based chemotherapies, but identification of patients likely to benefit from these therapies remains challenging [3-5]. Studies suggest that strong overexpression of EGFR rather than other factors including KRAS mutation status is a determinant factor for the treatment efficacy of cetuximab in NSCLC patients. However, it is still unclear whether positivity in immunohistochemistry (IHC) or Fluorescent in situ Hybridisation (FISH) score

(c) The Author(s). 2019 Open Access This article is distributed under the terms of the Creative Commons Attribution 4.0 International License (http://creativecommons.org/licenses/by/4.0/), which permits unrestricted use, distribution, and reproduction in any medium, provided you give appropriate credit to the original author(s) and the source, provide a link to the Creative Commons license, and indicate if changes were made. The Creative Commons Public Domain Dedication waiver (http://creativecommons.org/publicdomain/zero/1.0/) applies to the data made available in this article, unless otherwise stated. 
and/or squamous histology can be reliably predictive, presumably due to the heterogeneity of EGFR expression within tumors and/or limitations related to biopsy-based assessment such as limited tissue sampling [6, 7]. Another approach that could assess EGFR status within the entire tumor throughout the body could potentially provide more comprehensive information to predict whether a patient will respond to cetuximab treatment.

Molecular imaging with radiolabeled antibodies, including immuno-positron emission tomography (PET) imaging, can provide quantitative information about antibody uptake at a whole-body level in a non-invasive fashion [8]. ImmunoPET has shown potential for the assessment of biomarker expression status and/or prediction of clinical response [9, 10]. Studies found a significant association between the tumor uptake of copper-64 $\left({ }^{64} \mathrm{Cu}\right)$ labeled cetuximab $\left(\left[{ }^{64} \mathrm{Cu}\right] \mathrm{Cu}\right.$-DOTA-cetuximab) and the expression levels of EGFR protein in cervical cancer cell lines [11] and in xenograft mouse models with various cancer types $[12,13]$. By contrast, some studies have found disparity between the expression levels of EGFR and tumor uptake of radiolabeled cetuximab in several tumor xenograft models from different origins, implying the influence of other factors such as pharmacokinetics and dynamics for cetuximab accumulation in tumors $[14,15]$.

Considering the disease heterogeneity of NSCLC, the applicability of $\left[{ }^{64} \mathrm{Cu}\right] \mathrm{Cu}$-DOTA-cetuximab for non-invasive assessment of EGFR expression status in NSCLC warrants further validation in pre-clinical models. In this study, we evaluated the usefulness of $\left[{ }^{64} \mathrm{Cu}\right] \mathrm{Cu}$-DOTA-cetuximab for the selection of EGFR-overexpressing NSCLC tumors using xenograft mouse models with human NSCLC cell lines having various EGFR protein expression levels.

\section{Methods}

Cetuximab was kindly provided by Merck KgaA (Darmstadt, Germany). The bifunctional chelating agent p-SCN-BnDOTA, or 2-(4-isothiocyanatobenzyl)-1,4,7,10-tetraazacyclododecane-1,4,7,10-tetraacetic acid, was purchased from Macrocyclics (Dallas, TX, USA). Copper-64 (150-300 MBq) was produced on a biomedical cyclotron CYPRIS HM-18 (Sumitomo Heavy Industries Ltd., Tokyo, Japan) at Gunma University Hospital. Indium-111, in form of $\mathrm{InCl}_{3}(74 \mathrm{MBq} /$ $\mathrm{mL}$ ) was obtained from Nihon Medi-Physics (Tokyo, Japan).

\section{Cell lines and xenografts}

The animal studies were performed in accordance with our institutional guidelines and were approved by the Local Animal Care Committee of Gunma University (approval number: 17-035). Human NSCLC cell lines H358 (bronchioalveolar carcinoma, ATCC CRL-5807), H441 (papillary adenocarcinoma, ATCC HTB-174), H460 (large cell lung cancer, ATCC HTB-177), H520 (squamous cell carcinoma, ATCC HTB-182), H1299 (carcinoma, ATCC
CRL-5803), H1650 (adenocarcinoma; bronchoalveolar carcinoma, ATCC CRL-5883), and HCC827 (adenocarcinoma, ATCC CRL-2868) were obtained from ATCC (Manassas, VA, USA), and EBC1 (squamous cell lung carcinoma, JCRB0820) was obtained from Japanese Collection of Research Bioresources (Tokyo, Japan). All cell lines were grown monolayers in RPMI 1640 medium (Wako, Osaka, Japan) supplemented with $10 \%$ heat-inactivated FBS (Nichirei Bioscience, Tokyo, Japan) and 1\% antibiotic $(0.1 \mathrm{mg} / \mathrm{mL}$ penicillin and $100 \mathrm{U} / \mathrm{mL}$ streptomycin, Wako). The EGFR-null H520 cell line was used as a negative control to assess non-specific tumor uptake of radiotracer. All cell lines were cultured in a humidified atmosphere comprising $5 \% \mathrm{CO}_{2}$ and $95 \%$ air at $37^{\circ} \mathrm{C}$. Five-weeks-old female athymic Balb/c nude mice (17-20 g) were purchased from Japan CLEA (Tokyo, Japan) or Japan SLC (Shizuoka, Japan) and allowed to acclimatize for one week in the animal facility before any intervention was initiated. Mice were socially housed (4-5 animals per cage) in cages in an air-conditioned room at $28^{\circ} \mathrm{C}$ under a $12 \mathrm{~h}$ light/dark cycle with access to food and tap water ad libitum during all the experiment. Lung tumor xenografts were prepared by subcutaneous injection of $5 \times 10^{6}$ cells in $100 \mu \mathrm{L}$ PBS suspension in the dorsal flank of the mice in awake. Mice were randomly assigned to each experiment when the tumor size become approximately 100 $300 \mathrm{~mm}^{3}$ (2-4 week after the tumor implantation).

\section{Westernblot analysis for EGFR expression}

Xenografts mice ( $n>2$ for each tumor) were euthanized by cervical dislocation and tumors were collected. The western blot analysis was performed according to the procedure previously described [12]. Anti-EGFR (\#2232; Cell Signaling, Beverly, MA, USA) or anti $\beta$-actin (clone AC-15; Sigma-Aldrich, Saint Louis, MO, USA) was used as primary antibody. Membranes were visualized by scanning using the ImageQuant ${ }^{\mathrm{m}}$ LAS 4010 imager (GE Healthcare, Piscataway, NJ, USA) and the obtained bands were densimetry analyzed using ImageJ 1.47 software. The data were normalized over EGFR-null control H520. Based on the adjusted band density, the EGFR expression levels were classified in three categories; $>20$ : highly-overexpressing, 10 to 20: high, 1 to 10: low to moderate.

\section{DOTA conjugation}

Cetuximab $(2 \mathrm{mg} / \mathrm{mL})$ was buffer-exchanged into boratebuffered saline (0.1 M, pH 8.5) in Vivaspin (Sartorius Stedim Biotech, Aubagne, France). To the concentrated cetuximab was added p-SCN-Bn-DOTA dissolved in N,N-dimethylformamide (10:1 to cetuximab). The resulting mixture was incubated overnight at $37^{\circ} \mathrm{C}$, and then unconjugated DOTA was removed by using size-exclusion column (Bio-spin 6 Tris column, Bio-Rad Laboratories, Hercules, CA, USA) and 
ultrafiltration (Vivaspin). The protein concentration of the resulting DOTA-cetuximab was determined by using a Nanodrop spectrophotometer (Thermo Scientific, Wilmington, DE, USA).

The immunoreactivity of DOTA-cetuximab was evaluated in a NSCLC cell line (H460) according to a method described previously [16]. No significant effect of DOTA-conjugation was observed.

\section{Preparation of ${ }^{64} \mathrm{Cu}$ or ${ }^{111}$ In-labled DOTA-cetuximab} For ${ }^{64} \mathrm{Cu}$ labeling, DOTA-cetuximab $(500 \mu \mathrm{g})$ was dissolved in sodium acetate buffer $(0.25 \mathrm{M}, \mathrm{pH} 5.5)$ and then added to the dried ${ }^{64} \mathrm{CuCl}_{2}(150-300 \mathrm{MBq})$. The resulting mixture was incubated for $1 \mathrm{~h}$ at $40{ }^{\circ} \mathrm{C}$. An aqueous solution of EDTA $(100 \mathrm{mM}, 5 \mu \mathrm{L})$ was added to quench the unconjugated ${ }^{64} \mathrm{Cu}$. Purification of $\left[{ }^{64} \mathrm{Cu}\right] \mathrm{Cu}$-DOTAcetuximab was carried out using PD-10 desalting column (GE Healthcare). [ $\left.{ }^{111} \mathrm{In}\right]$ In-DOTA-cetuximab was obtained by a similar procedure. The radiochemical yield and radiochemical purity were determined using an instant TLC developed with saline. After purification, the radiochemical purities of both $\left[{ }^{64} \mathrm{Cu}\right] \mathrm{Cu}$-DOTA-cetuximab and $\left[{ }^{111} \mathrm{In}\right]$ In-DOTA-cetuximab were more than 99\%. The specific activity of the final product per milligram cetuximab was $2-3 \mathrm{MBq}$ for ${ }^{111} \mathrm{In}$. Due to the varying radiochemical yields, the specific activity of $\left[{ }^{64} \mathrm{Cu}\right] \mathrm{Cu}$-DOTA-cetuximab ranged $30-200 \mathrm{MBq} / \mathrm{mg}$.

\section{Biodistribution study}

To detect and examine in vivo behavior of radiolabeledcetuximab in xenografts with various lung cancer cell lines, [ $\left.{ }^{111} \mathrm{In}\right] \mathrm{In}-\mathrm{DOTA}$-cetuximab (protein dose: $20 \mu \mathrm{g}$ ) were intravenously injected with $30 \mathrm{kBq}$ via the tail vein in awake mice ( $n \geq 5$ for each group). Mice were euthanized by decapitation at $48 \mathrm{~h}$ after injection. Tissues of interest were collected and weighed, and the radioactivity was measured using an automated $\gamma$-counter ARC-7001 (Hitachi Aloka Medical, Tokyo, Japan). The radiotracer uptake was expressed as percentage of injected dose/g of tissue (\%ID/g).

\section{PET imaging}

To study PET usefulness for the assessment of EGFR expression level in vivo, xenografts of lung cancer cell lines $(n=2)$ were intravenously injected with $2-20 \mathrm{MBq}$ $\left[{ }^{64} \mathrm{Cu}\right] \mathrm{Cu}$-DOTA-cetuximab via the tail vein in awake. To minimize the influence of specific activity, protein dose was fixed to $100 \mu \mathrm{g}$ by the addition of nonradiolabeled cetuximab. Considering the pharmacokinetics of monoclonal antibody [8] and the physical half-life of ${ }^{64} \mathrm{Cu}(12.7 \mathrm{~h})$, PET images were taken $48 \mathrm{~h}$ after injection. After anesthetization by isoflurane inhalation $(2.5 \%$ in an air mixture), mice were imaged with a smallanimal PET scanner (Transaxial FOV: $10 \mathrm{~cm}$, axial FOV: $12.7 \mathrm{~cm}$, resolution at the center of FOV: $1.4 \mathrm{~mm}$,
Inveon, Siemens, Knoxville, TN, USA). To obtain images with equivalent qualities, the acquisition time was adjusted based on the activity dose. The acquisition time was $20 \mathrm{~min}$, $60 \mathrm{~min}$, or $120 \mathrm{~min}$ for $20 \mathrm{MBq}$, $4 \mathrm{MBq}$, or 2-3 MBq activity dose, respectively. In all studies, PET scanning was performed with animals over a heating pad heated at $37^{\circ} \mathrm{C}$. After the PET scan, mice were euthanized by cervical dislocation. The energy window was set between 350 and $650 \mathrm{keV}$. The imaging data were reconstructed using a 3-D ordered-subsets expectation maximization algorithm. Attenuation correction and scattering correction were not applied. All images were quantified for tumor radiotracer uptake using the Inveon Research Workplace workstation (Siemens). Uptake of $\left[{ }^{64} \mathrm{Cu}\right] \mathrm{Cu}$-DOTA-cetuximab in the tumor was expressed as average of standardized uptake values (SUVmean). The SUV was determined by using the following equation: $\mathrm{SUV}=$ activity in a $\mathrm{ROI}(\mathrm{MBq} / \mathrm{cc}) /[$ injected dose $(\mathrm{MBq})$ /body weight $(\mathrm{g})$ ]. Region of interests (ROI) were manually drawn to contour the tumors three times each by two investigators $(\mathrm{HH}, 10$ years of experience, AK2, 1 year of experience). Tumor outlines were defined by the pixel containing SUV higher than 0.6. There was no noticeable difference in intra- and interobserver variability.

\section{Statistical analysis}

The GraphPad Prism software (GraphPad Software, La Jolla, CA, USA) was used for statistical analysis. Data are expressed as means \pm SDs where appropriate. In the biodistibution study with $\left[{ }^{111} \mathrm{In}\right] \mathrm{In}$-DOTA-cetuximab, comparison of means was performed using one-way ANOVA followed by Tukey's test. For the comparison between tumor $\left[{ }^{111} \mathrm{In}\right]$ In-DOTA-cetuximab uptake, $\left[{ }^{64} \mathrm{Cu}\right] \mathrm{Cu}$-DOTA-cetuximab uptake and adjusted EGFR band density, simple correlations between variables were analyzed using Pearson's correlation coefficient. $P$-values $<0.05$ were considered statistically significant.

\section{Results \\ EGFR expression in NSCLC cell lines}

Immunoblot analysis of the xenograft tumors showed that the eight NSCLC cell lines express various levels of EGFR (Fig. 1). Semi-quantitative confirmation of EGFR expression showed that HCC827 surpasses the rest (EGFR band density of 25.0, relative to EGFR-null H520), followed by H1650 and EBC-1 (13.5 and 10.9, respectively). Other EGFR-positive cell lines showed modest expression levels ranging from 6.53 to 8.86 .

\section{Biodistribution of $\left[{ }^{111} \mathrm{In}\right]$ in-DOTA-cetuximab}

Figure 2 summarizes $\left[{ }^{111} \mathrm{In}\right] \mathrm{In}$-DOTA-cetuximab uptakes in major organs and tumors $48 \mathrm{~h}$ after injection in NSCLC tumor xenografts ( $n=5$ to 7 /group). The tumor uptake levels of $\left[{ }^{111} \mathrm{In}\right]$ In-DOTA-cetuximab in EGFR- 


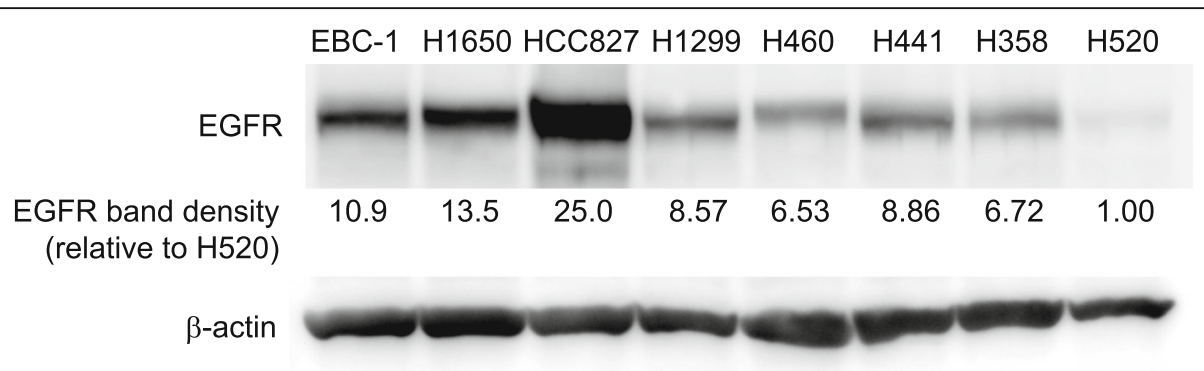

Fig. 1 Epidermal growth factor receptor (EGFR) expression in eight non-small cell lung cancer (NSCLC) cell lines. Densitometric intensities of EGFR are presented as folds relative to H520 band density (1.0). $\beta$-actin was used as a loading control

positive xenografts were significantly higher than that of EGFR-null H520 tumors $(P<0.05)$. The uptake level of $\left[{ }^{111} \mathrm{In}\right]$ In-DOTA-cetuximab in the EGFR highlyoverexpressed $\mathrm{HCC} 827$ tumor $(n=7)$ was significantly higher than those in other cell lines except for EBC-1 $(26.9 \pm 3.10 \% \mathrm{ID} / \mathrm{g}, P<0.05)$. Although large variation was observed, EBC-1 xenografts $(n=5)$, which had relatively high EGFR expression levels, showed $\left[{ }^{111} \mathrm{In}\right] \mathrm{In}$ DOTA-cetuximab uptake levels significantly higher than xenografts with low to moderate EGFR expression levels (H358, H441, H460) $(23.3 \pm 7.63 \% \mathrm{ID} / \mathrm{g}, P<0.05)$. H1650 also showed a relatively high uptake level of $\left[{ }^{111} \mathrm{In}\right] \mathrm{In}$ DOTA-cetuximab $(18.4 \pm 3.59 \% \mathrm{ID} / \mathrm{g}, \mathrm{n}=5)$ although the difference was not statistically significant compared to the cell lines with moderate to low EGFR expression levels (H358, H441, H460, and H1299). The other tumors derived from 4 NSCLC cell lines with moderate to low EGFR expression levels showed comparable uptake levels of $\left[{ }^{111} \mathrm{In}\right] \mathrm{In}$-DOTA-cetuximab. The radioactivity uptakes of H358 (n=6), H441 (n=6), H460 (n=6), and H1299 $(n=6)$ tumors were $15.1 \pm 0.96 \% \mathrm{ID} / \mathrm{g}, 14.0 \pm$ $3.77 \% \mathrm{ID} / \mathrm{g}, 13.2 \pm 5.56 \% \mathrm{ID} / \mathrm{g}$, and $16.7 \pm 3.46 \% \mathrm{ID} / \mathrm{g}$, respectively. Accumulation in normal organs was similar in all groups.

\section{PET imaging of $\left[{ }^{64} \mathrm{Cu}\right] \mathrm{cu}$-DOTA-cetuximab}

The whole-body distribution and tumor-targeting efficiency of cetuximab was visualized non-invasively using small-animal PET imaging at $48 \mathrm{~h}$ after injection of $\left[{ }^{64} \mathrm{Cu}\right] \mathrm{Cu}$-DOTA-cetuximab in mice with NSCLC xenografts ( $n=2$ per group). As shown in Fig. 3, PET imaging clearly depicted the high uptake of $\left[{ }^{64} \mathrm{Cu}\right] \mathrm{Cu}$-DOTAcetuximab in HCC827 xenografts, which highly overexpress EGFR. Quantification of the PET images revealed that tumor uptakes (SUVmean of $\left[{ }^{64} \mathrm{Cu}\right] \mathrm{Cu}$-DOTAcetuximab) in HCC827 tumors were exceptionally high (3.17 and 4.41). Although H1650 showed relatively high SUVmean values (1.93 and 2.17), other xenografts of low

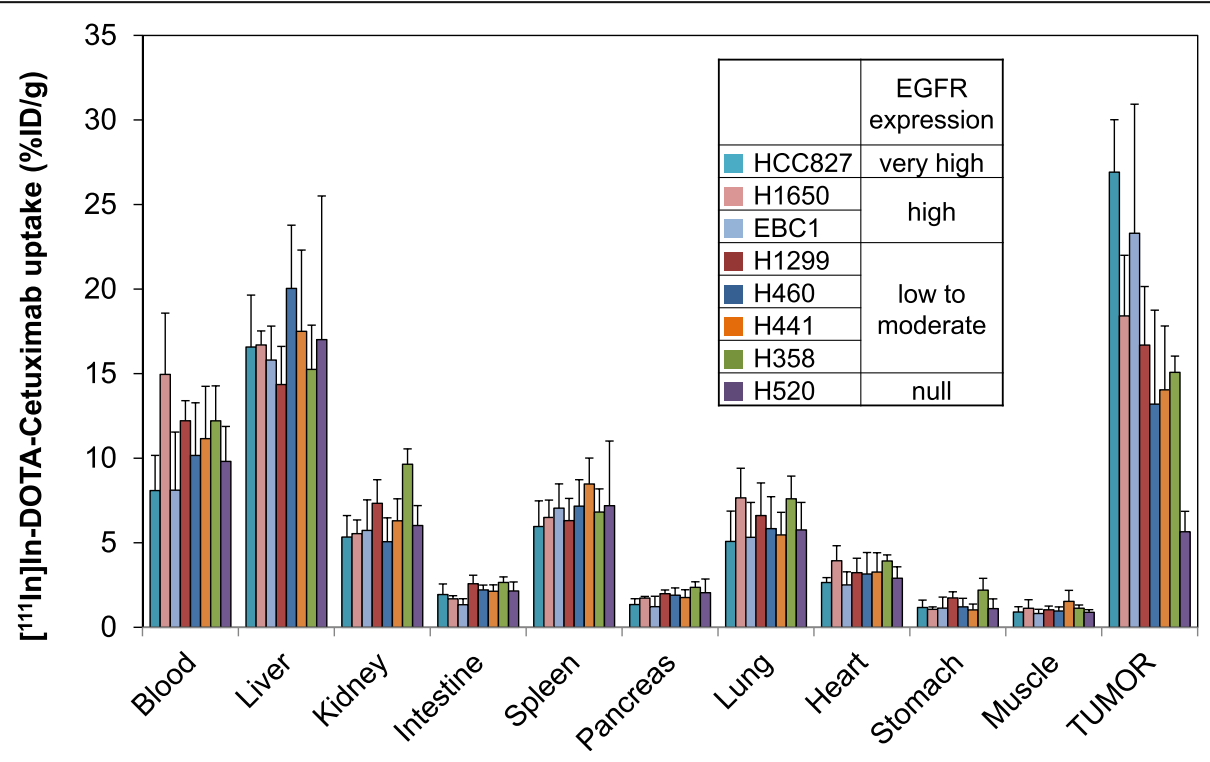

Fig. 2 Biodistribution of $\left.{ }^{111} \mathrm{In}\right] \mathrm{In}$-DOTA-cetuximab at $48 \mathrm{~h}$ in mice xenograft models with non-small cell lung cancer (NSCLC) tumors with varying epidermal growth factor receptor (EGFR) expression levels. Each data point represents the mean \pm SD of $n=5$ to 7 per tumor model 


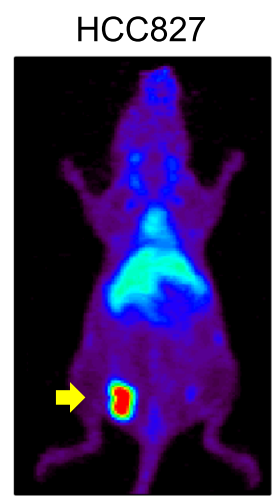

$\mathrm{H} 460$

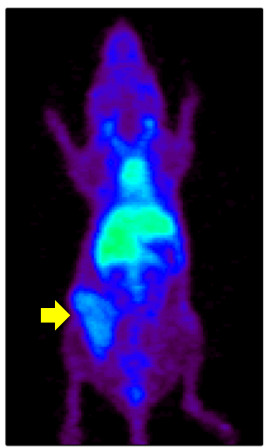

$\mathrm{H} 1650$

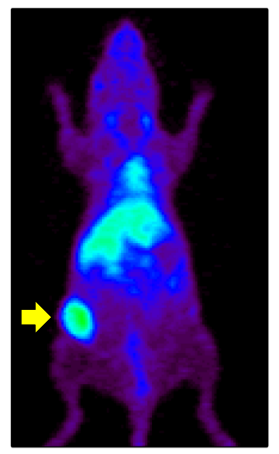

$\mathrm{H} 441$

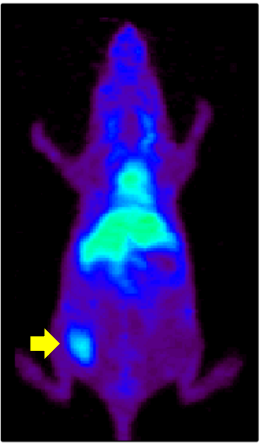

EBC-1

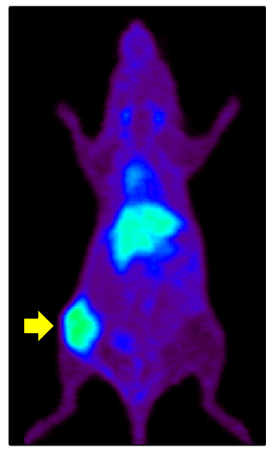

H358

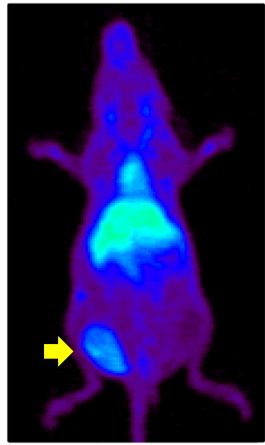

H1299

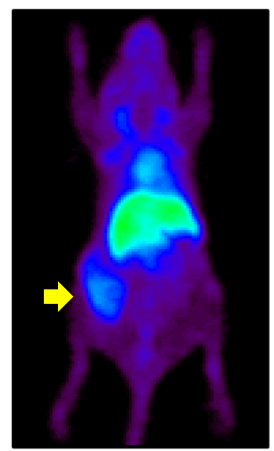

SUV

6.1

3.5

1.2

Fig. 3 Representative $\left[{ }^{64} \mathrm{Cu}\right.$ CU-DOTA-cetuximab positron emission tomography (PET) images in mice xenograft models with non-small cell lung cancer (NSCLC) tumors with varying epidermal growth factor receptor (EGFR) expression levels at $48 \mathrm{~h}$. Arrows indicate the location of tumors

to moderate EGFR expression showed SUVmean values comparable to those of EGFR-null H520 (range 0.871.66, number of mice analyzed: $10 / 10)$.

\section{Comparison of radiolabeled cetuximab tumor uptake with EGFR expression level}

Figure 4 shows the relationship between tumor $\left[{ }^{111} \mathrm{In}\right]$ In-DOTA-cetuximab uptake or $\left[{ }^{64} \mathrm{Cu}\right] \mathrm{Cu}$ DOTA-cetuximab uptake and adjusted EGFR band density. The linear relationships with a positive slope in both graphs indicate the positive correlation between variables. Tumor uptake of $\left[{ }^{111} \mathrm{In}\right] \mathrm{In}$-DOTA-cetuximab uptake strongly correlated with the adjusted EGFR band density $(\mathrm{r}=0.893, p<0.005)$. A strong correlation was also found between tumor uptake of $\left[{ }^{64} \mathrm{Cu}\right] \mathrm{Cu}$ DOTA-cetuximab and adjusted EGFR band density $(\mathrm{r}=0.915, \mathrm{p}<0.005)$. A moderate correlation was observed between $\left[{ }^{111} \mathrm{In}\right] \mathrm{In}$-DOTA-cetuximab tumor uptake and $\left[{ }^{64} \mathrm{Cu}\right] \mathrm{Cu}$-DOTA-cetuximab tumor uptake $(r=0.694)$.
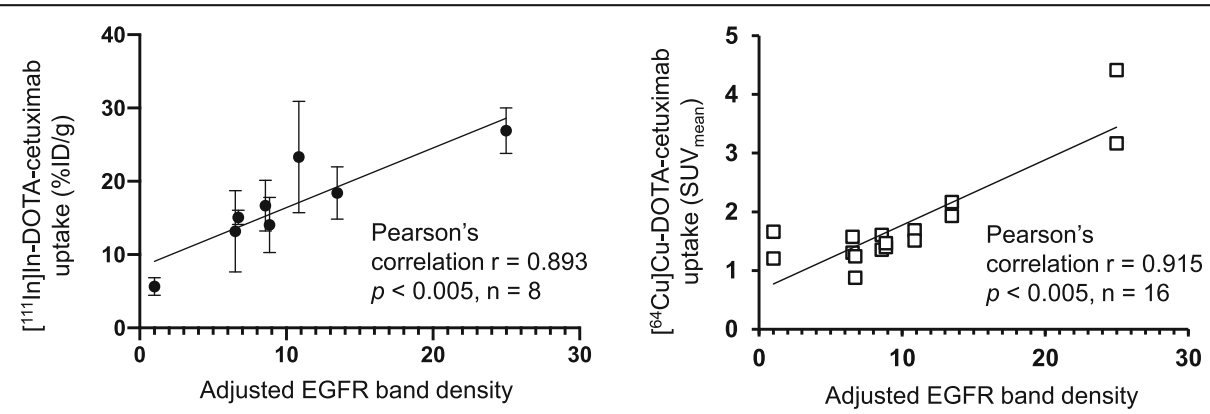

Fig. 4 Correlation between epidermal growth factor receptor (EGFR) expression and tumor uptake of radiolabeled cetuximab. (a) A significant correlation of EGFR expression level and tumor uptake of $\left[{ }^{111} \mathrm{In}\right] \mathrm{In}$-DOTA-cetuximab was noted within tumor models of non-small cell lung cancer. Each data represents the mean \pm SD of $n=5$ to 7 per tumor model. (b) Tumor uptake of $\left[{ }^{64} \mathrm{Cu}\right] \mathrm{Cu}$-DOTA-cetuximab in positron emission tomography (PET) (mean standardized uptake values [SUV mean]) is correlated with the EGFR expression level. Each data point represents SUVmean of each NSCLC tumor (8 cell lines, $n=2$ per group) left panel: (a), right panel (b) 


\section{Discussion}

This study demonstrated the association between NSCLC tumor uptake of radiolabeled cetuximab and EGFR protein expression levels in a xenograft mouse model. Distinguishably high accumulation of radiolabeled cetuximab was noted in EGFR-highly-overexpressing tumors in comparison to the tumors with low and moderate EGFR expression levels, allowing for clear visualization of the tumor in PET imaging. These results suggest the potential usefulness of cetuximab immuno-PET for non-invasive prediction of cetuximab uptake in NSCLC.

The biodistribution study with $\left[{ }^{111} \mathrm{In}\right] \mathrm{In}$-DOTA-cetuximab suggested that radioactivity uptake in the NSCLC xenograft tumors sharply reflects the corresponding EGFR protein expression levels. This result is in line with previous studies of radiolabeled cetuximab employed in colorectal cancer models [12, 17]. The significantly high uptake of [ $\left.{ }^{111} \mathrm{In}\right]$ In-DOTA-cetuximab in EGFR-highly-overexpressing HCC827 in comparison with xenograft tumors with low to moderate EGFR expression levels suggests the potential of $\left[{ }^{64} \mathrm{Cu}\right] \mathrm{Cu}$-DOTA-cetuximab immuno-PET for detection of EGFR expression status in NSCLC. The large variation in $\left[{ }^{111} \mathrm{In}\right] \mathrm{In}$-DOTA-cetuximab uptake observed within EBC-1 xenografts is perhaps due to the inter-subject heterogeneity of EGFR expression levels. Further investigation such as a side-by-side comparison between $\left[{ }^{111} \mathrm{In}\right] \mathrm{In}$-DOTA-cetuximab distribution and EGFR expression ex vivo might provide some clues; however, it is beyond the scope of the current study. Nevertheless, this inter-subject difference in ${ }^{[111}$ In] In-DOTA-cetuximab uptake indicates that radiolabeled cetuximab potentially reflects the inter- or intrapatient heterogeneity of EGFR expression level.

The quantitative analysis of the PET study showed a strong correlation with the adjusted EGFR band density, which is in agreement with the biodistribution study. HCC827 tumors showed exceptionally high SUVmean levels compared to other tumors, which reinforced the potential of $\left[{ }^{64} \mathrm{Cu}\right] \mathrm{Cu}$-DOTA-cetuximab-PET for the identification of NSCLC patients suitable for cetuximab therapy. Meanwhile, there was a small variation in SUVmean values between EGFR low to high expressing tumors. Since various factors may influence tumor uptake of radiolabeled antibodies-such as extravasation from tumor capillaries, diffusion and binding within the tumor interstitium, plasma clearance, internalization, and catabolism in tumor cells [18, 19], and morphological or physical barriers-specific binding to the antigen may not be the dominant factor determining cetuximab uptake level in NSCLC tumor with EGFR expression on its cell surface below a certain level. Indeed, H520 cells form highly vascularized tumors [20]. In addition, because SUV is standardized for body weight, the numerical range of SUV values in mice are not equivalent to those in human. A number of clinical studies have been demonstrated that SUV values for tumor uptake of radiolabeled antibodies vary widely among lesions [9,21]. Although clinical confirmation is necessary, it is highly likely that $\left[{ }^{64} \mathrm{Cu}\right] \mathrm{Cu}$-DOTA-cetuximab shows SUVmean values of NSCLC tumors in a range sufficient to differentiate cetuximab responsive cases from non-responsive cases.

Another factor limiting the range of SUVmean values would be the low specific activity of $\left[{ }^{64} \mathrm{Cu}\right] \mathrm{Cu}$-DOTAcetuximab $(4.5-30 \mathrm{GBq} / \mu \mathrm{mol})$. This necessitated high protein dose $(100 \mu \mathrm{g} / \mathrm{head})$ administration in the PET study, which may have competitively inhibited the radiotracer uptake due to receptor saturation in low-EGFR-expressing tumors [22-24]. This difference may also account for the discrepancy in the radiotracer tumor uptake between the biodistiribution study and PET imaging, which showed only a moderate correlation. Tamura et al. [25] reported much higher specific activity of $\left[{ }^{64} \mathrm{Cu}\right] \mathrm{Cu}$-DOTA-trastuzumab $(350 \mathrm{GBq} / \mu \mathrm{mol})$. These results indicate that optimization of the ${ }^{64} \mathrm{CuCl}_{2}$ production process is necessary to obtain clinically acceptable specific activity of $\left[{ }^{64} \mathrm{Cu}\right] \mathrm{Cu}$-DOTA-cetuximab in our facility. However, the low specific activity would not affect clinical evaluation of radiotracer uptake because high amount of protein (up to $50 \mathrm{mg}$ ) are required to prevent rapid clearance and allow for tumor accumulation of radiolabeled antibodies [21, 26].

Although several large clinical NSCLC trials evaluating the efficacy of chemotherapy plus cetuximab suggested the value of a high EGFR expression level determined by quantitative analysis of IHC or FISH as a predictive biomarker, the robustness of this theory is still controversial $[3,27,28]$. A recently closed, large, randomized phase-3 trial (SWOG S0819) failed to show the clinical benefit of the addition of cetuximab to platinum-based chemotherapy even within the patient subgroup with high EGFR FISH scores [5]. The use of IHC or FISH scores has several concerns such as the definition of positive test results, reproducibility, and the discrepancy between biomarker status determined based on IHC and FISH scores [7], which may have contributed to the subgroup misclassification and led to the controversial results among studies. Unlike histological analysis, immuno-PET can noninvasively reflect dynamic biomarker status at the wholebody level. In case of NSCLC, PET imaging with $\left[{ }^{64} \mathrm{Cu}\right] \mathrm{Cu}$-DOTA-cetuximab by itself could predict the response to therapy as it is indicative of cetuximab tumor accessibility while the therapeutic response are not associated with biomolecular characteristics such as the status of KRAS, PTEN, and EGFR mutations. Therefore, addition of immuno-PET scanning using $\left[{ }^{64} \mathrm{Cu}\right] \mathrm{Cu}$ DOTA-cetuximab to the workup protocol may help increase the accuracy of biomarker status assessment in NSCLC patients. Comparative studies to evaluate the predictive values of IHC and/or FISH scores separately or in 
combination with immuno-PET based analysis are required to test this hypothesis.

There are several limitations in our study. First, xenografts of established human tumor cell lines may have different characteristics from those of primary human tumors, and thereby EGFR expression levels determined here is not directly comparable to the EGFR-positivity criteria commonly used in clinical setting. Further studies in more clinically relevant models are warranted [4]. In addition, the predictive value of $\left[{ }^{64} \mathrm{Cu}\right] \mathrm{Cu}$-DOTAcetuximab immuno-PET for cetuximab treatment was not determined. Finally, although suitable main positron energy of ${ }^{64} \mathrm{Cu}(653 \mathrm{keV})$ can provide PET images with spatial resolution better than ${ }^{86} \mathrm{Y}(\mathrm{Emax}=3.1 \mathrm{MeV}$, with an additional $\gamma$-emission of $1.08 \mathrm{MeV}$ (83\% abundance)), another positron emitter suitable for antibody imaging [22], there are several concerns regarding the use of ${ }^{64} \mathrm{Cu}$ for imaging tumor uptake of antibodies, such as its limited availability and relatively short half-life $(12.7 \mathrm{~h})$. Detection of lung legions might be hindered by accumulation of radioactivity in the liver due to the relatively weak in vivo stability of $\left[{ }^{64} \mathrm{Cu}\right] \mathrm{Cu}$-DOTA. But the use of ${ }^{64} \mathrm{Cu}$ is a valuable option especially in facilities at which other longer-lived positron emitter isotopes such as ${ }^{89} \mathrm{Zr}$ $\left(398 \mathrm{keV}, \mathrm{t}_{1 / 2}=3.3 \mathrm{~d}\right)$ and ${ }^{86} \mathrm{Y}$ are not available.

\section{Conclusion}

This study has demonstrated that cetuximab uptake in NSCLC tumors can be assessed by PET using ${ }^{64} \mathrm{Cu}-\mathrm{la}$ beled cetuximab. Significantly high uptake of $\left[{ }^{64} \mathrm{Cu}\right] \mathrm{Cu}$ DOTA-cetuximab was noted in NSCLC tumors with very high EGFR expression levels compared to tumors with medium or low EGFR expression levels. These results suggest that immuno-PET with $\left[{ }^{64} \mathrm{Cu}\right] \mathrm{Cu}$-DOTAcetuximab may provide additional information for selection of patients with advanced NSCLC most likely to benefit from cetuximab treatment.

\section{Abbreviations \\ DOTA or p-SCN-Bn-DOTA: 2-(4-isothiocyanatobenzyl)-1,4,7,10- \\ tetraazacyclododecane-1,4,7,10-tetraacetic acid; EGFR: Epidermal growth factor receptor; IHC: Immunohistochemistry, FISH: Fluorescent in situ Hybridisation; NSCLC: Non-small cell lung cancer; PET: Positron Emission Tomography; ROI: Region of interest; SUV: Standardized uptake value; TKl: Tyrosine kinase inhibitor}

\section{Acknowledgements}

We thank Mr. Takashi Ogasawara (Cyclotron Facility, Gunma University Hospital) for the production of ${ }^{64} \mathrm{Cu}$.

\section{Authors' contributions}

$A Y, A A$, and $\mathrm{HH}$ participated in the design of the study. Data acquisition was done by $A Y, A A, Y H, A B$, Ratianto, EK, RS, AK1, and HH. Data analysis was done by $A Y, A A, A K 2$, and $H H$. AY drafted the manuscript. $A A$ and $H H$ revised the manuscript critically. TH, YS, NI and TY contributed reagents/materials/ analysis tools. All authors read and approved the final manuscript.

\section{Funding}

Not applicable.

\section{Availability of data and materials}

The datasets used and/or analysed during the current study are available from the corresponding author on reasonable request.

\section{Ethics approval}

The animal studies were performed in accordance with our institutional guidelines and were approved by the Local Animal Care Committee of Gunma University (approval number: 17-035).

\section{Consent for publication}

Note applicable.

\section{Competing interests}

The authors declare that they have no competing interests.

\section{Author details}

'Department of Bioimaging Information Analysis, Gunma University Graduate School of Medicine, 3-39-22 Showa-machi, Maebashi 371-8511, Japan. 2Present address: Texas Therapeutics Institute, The Brown Foundation Institute of Molecular Medicine, The University of Texas Health Science Center at Houston, 1881 East Road, Houston, TX 77054, USA. ${ }^{3}$ Department of Diagnostic Radiology and Nuclear Medicine, Gunma University Graduate School of Medicine, 3-39-22 Showa-machi, Maebashi 371-8511, Japan. ${ }^{4}$ Present address: Department of Nuclear Medicine and Molecular Imaging, Faculty of Medicine, Universitas Padjadjaran, Bandung, West Java 40161, Indonesia. ${ }^{5}$ Oncology and Stem Cell Working Group, Faculty of Medicine, Universitas Padjadjaran, Bandung, West Java 40161, Indonesia. ${ }^{6}$ Project "Medical Radioisotope Application", Department of Radiation-Applied Biology Research, Takasaki Advanced Radiation Research Institute, Quantum Beam Advanced Research Directorate, National Institutes for Quantum and Radiological Science and Technology, 1233 Watanuki, Takasaki 370-1292, Japan.

Received: 11 July 2019 Accepted: 1 October 2019

Published online: 24 October 2019

\section{References}

1. Siegel RL, Miller KD, Jemal A. Cancer statistics, 2018. CA: A Cancer Journal for Clinicians. 3rd ed. 2018;68:7-30.

2. Herbst RS, Morgensztern D, Boshoff C. The biology and management of non-small cell lung cancer. Nature. 2018;553:446.

3. Pujol J-L, Pirker R, Lynch TJ, Butts CA, Rosell R, Shepherd FA, et al. Metaanalysis of individual patient data from randomized trials of chemotherapy plus cetuximab as first-line treatment for advanced non-small cell lung cancer. Lung Cancer. 2014;83:211-8.

4. Amendt C, Staub E, Friese-Hamim M, Storkel S, Stroh C. Association of EGFR expression level and Cetuximab activity in patient-derived Xenograft models of human non-small cell lung Cancer. Clin Cancer Res. 2014;20: 4478-87.

5. Herbst RS, Redman MW, Kim ES, Semrad TJ, Bazhenova L, KO MD, et al. Cetuximab plus carboplatin and paclitaxel with or without bevacizumab versus carboplatin and paclitaxel with or without bevacizumab in advanced NSCLC (SWOG S0819): a randomised, phase 3 study. Lancet Oncol. 2018;19: 101-14.

6. Jamal-Hanjani M, Wilson GA, McGranahan N, Birkbak NJ, Watkins TBK, Veeriah S, et al. Tracking the evolution of non-small-cell lung Cancer. N Engl J Med. 2017;376:2109-21.

7. Chae YK, Arya A, Chiec L, Shah H, Rosenberg A, Patel S, et al. Challenges and future of biomarker tests in the era of precision oncology: can we rely on immunohistochemistry (IHC) or fluorescence in situ hybridization (FISH) to select the optimal patients for matched therapy? Oncotarget. 2017;8: 100863-98.

8. van Dongen GAMS, Visser GWM, Lub-de Hooge MN, de Vries EG, Perk LR. Immuno-PET: a navigator in monoclonal antibody development and applications. Oncologist. 2007;12:1379-89.

9. Bensch F, van der Veen EL, Lub-de Hooge MN, Jorritsma-Smit A, Boellaard R, Kok IC, et al. 89Zr-atezolizumab imaging as a non-invasive approach to assess clinical response to PD-L1 blockade in cancer. Nat Med. 2018;24: $1852-8$. 
10. Kurihara H, Hamada A, Yoshida M, Shimma S, Hashimoto J, Yonemori K, et al. ${ }^{64} \mathrm{Cu}$-DOTA-trastuzumab PET imaging and HER2 specificity of brain metastases in HER2-positive breast cancer patients. EJNMMI Res. 2015;5:8.

11. Eiblmaier M, Meyer LA, Watson MA, Fracasso PM, Pike $L$, Anderson CJ. Correlating EGFR expression with receptor-binding properties and internalization of 64Cu-DOTA-Cetuximab in 5 cervical Cancer cell lines. J Nucl Med. 2008:49:1472-9.

12. Achmad A, Hanaoka H, Yoshioka H, Yamamoto S, Tominaga H, Araki T, et al. Predicting cetuximab accumulation in KRAS wild-type and KRAS mutant colorectal cancer using 64Cu-labeled cetuximab positron emission tomography. Cancer Sci. 2011;103:600-5.

13. Cai W, Chen K, He L, Cao Q, Koong A, Chen X. Quantitative PET of EGFR expression in xenograft-bearing mice using ${ }^{64} \mathrm{Cu}$-labeled cetuximab, a chimeric anti-EGFR monoclonal antibody. Eur J Nucl Med Mol Imaging. 2007:34:850-8.

14. Aerts HJWL, Dubois $L$, Perk L, Vermaelen P, van Dongen GAMS, Wouters BG, et al. Disparity between in vivo EGFR expression and ${ }^{89} \mathrm{Zr}$-labeled Cetuximab uptake assessed with PET. J Nucl Med. 2008;50:123-31.

15. Niu G, Sun X, Cao Q, Courter D, Koong A, Le QT, et al. Cetuximab-based immunotherapy and Radioimmunotherapy of head and neck squamous cell carcinoma. Clin Cancer Res. 2010;16:2095-105.

16. Hanaoka H, Kuroki M, Yamaguchi A, Achmad A, lida Y, Higuchi T, et al. Fractionated Radioimmunotherapy with ${ }^{90} \mathrm{Y}$-labeled fully human anti-CEA antibody. Cancer Biother Radiopharm. 2014;29:70-6.

17. Ping Li W, Meyer LA, Capretto DA, Sherman CD, Anderson CJ. Receptorbinding, biodistribution, and metabolism studies of ${ }^{64} \mathrm{Cu}$-DOTA-cetuximab, a PET-imaging agent for epidermal growth-factor receptor-positive tumors. Cancer Biother Radiopharm. 2008;23:158-71.

18. Thurber GM, Schmidt M, Wittrup KD. Factors determining antibody distribution in tumors. Trends Pharmacol Sci. 2008;29:1-5.

19. Antibody tumor penetration. Transport opposed by systemic and antigenmediated clearance. Adv Drug Delivery Rev. 2008;60:1421-34.

20. Stapleton S, Milosevic M, Allen C, Zheng J, Dunne M, Yeung I, et al. A mathematical model of the enhanced permeability and retention effect for liposome transport in solid tumors. Chuu C-P, editor. PLoS One. 2013;8: e81157-10.

21. Dijkers EC, Oude Munnink TH, Kosterink JG, Brouwers AH, Jager PL, de Jong $J R$, et al. Biodistribution of ${ }^{89} \mathrm{Zr}$-trastuzumab and PET imaging of HER2positive lesions in patients with metastatic breast cancer. Clin Pharmacol Ther. 2010;87:586-92.

22. Nayak TK, Regino CAS, Wong K, Milenic DE, Garmestani K, Baidoo KE et al. PET imaging of HER1-expressing xenografts in mice with ${ }^{86} \mathrm{Y}$-CHXA"-DTPAcetuximab. Eur J Nucl Med Mol Imaging; 2010;37:1368-1376.

23. van Bueren JJL, Bleeker WK, Bøgh HO, Houtkamp M, Schuurman J, van de Winkel JGJ, et al. Effect of Target Dynamics on Pharmacokinetics of a Novel Therapeutic Antibody against the Epidermal Growth Factor Receptor: Implications for the Mechanisms of Action. Cancer Res. 2006;66:7630-8.

24. Hoeben BA, Molkenboer-Kuenen JD, Oyen WJ, Peeters WJ, Kaanders JH Bussink J, et al. Radiolabeled cetuximab: dose optimization for epidermal growth factor receptor imaging in a head-and-neck squamous cell carcinoma model. Int J Cancer. 2011;129:870-8.

25. Tamura K, Kurihara $\mathrm{H}$, Yonemori $\mathrm{K}$, Tsuda $\mathrm{H}$, Suzuki J, Kono $\mathrm{Y}$, et al. ${ }^{64} \mathrm{Cu}-$ DOTA-Trastuzumab PET imaging in patients with HER2-positive breast Cancer. J Nucl Med. 2013;54:1869-75.

26. Menke-van der Houven van Oordt CW, Gootjes EC, Huisman MC, Vugts DJ, Roth C, Luik AM, et al. ${ }^{89}$ Zr-cetuximab PET imaging in patients with advanced colorectal cancer. Oncotarget. 2015;6:30384-93.

27. Pirker R, Pereira JR, Pawel von J, Krzakowski M, Ramlau R, Park K, et al. EGFR expression as a predictor of survival for first-line chemotherapy plus cetuximab in patients with advanced non-small-cell lung cancer: analysis of data from the phase 3 FLEX study. Lancet Oncol. 2012;13:33-42.

28. Khambata-Ford S, Harbison CT, Hart LL, Awad M, Xu L-A, Horak CE, et al. Analysis of potential predictive markers of Cetuximab benefit in BMS099, a phase III study of Cetuximab and first-line Taxane/carboplatin in advanced non-small-cell lung Cancer. J Clin Oncol. 2010;28:918-27.

\section{Publisher's Note}

Springer Nature remains neutral with regard to jurisdictional claims in published maps and institutional affiliations.

\section{Ready to submit your research? Choose BMC and benefit from:}

- fast, convenient online submission

- thorough peer review by experienced researchers in your field

- rapid publication on acceptance

- support for research data, including large and complex data types

- gold Open Access which fosters wider collaboration and increased citations

- maximum visibility for your research: over $100 \mathrm{M}$ website views per year

At BMC, research is always in progress.

Learn more biomedcentral.com/submissions 